\title{
CHARACTERIZATION OF FATIGUE IN WOMEN WITH BREAST NEOPLASIA SUBMITTED TO CHEMOTHERAPY UNDER THE BEHAVIORAL DIMENSION OF THE PIPER SCALE-REVISED
}

${ }^{1}$ Cristina Albuquerque Douberin, *,2Liniker Scolfild Rodrigues da Silva, ${ }^{3}$ Talita Munique de Melo Rodrigues, ${ }^{4}$ Edivaldo Bezerra Mendes Filho, ${ }^{5}$ Adriana Maria dos Santos, ${ }^{6}$ Thayná da Silva Constantino, ${ }^{7}$ Yanna Georgia Crispiniano Ferreira da Silva, ${ }^{8}$ Adriane Farias Patriota, ${ }^{2}$ Luiz Neves Silveira Filho, ${ }^{10}$ Luciana Maria da Silva, ${ }^{11}$ Rosimery Rodrigues de Almeida Mendes, ${ }^{12}$ Lívia Maria Almeida de Oliveira

${ }^{1}$ Nurse, Master in Nursing from the University of Pernambuco/Paraíba State University (UPE/UEPB), Recife, Pernambuco (PE)/Campina Grande, Paraíba (PB), Brazil; ${ }^{2}$ Specialist in Obstetric Nursing in the Residency modality from the Nursing School Nossa Senhora das Graças/University of Pernambuco (FENSG/UPE). Public Health Officer, Specialist in Collective Health in the Residency modality from the Medical Sciences College (FCM)/UPE. Recife, Pernambuco (PE), Brazil; ${ }^{3}$ Nursing, Resident in the Program of Residence in Children Healthcare from the Institute of Integral Medicine Professor Fernando Figueiras (IMIP). Recife, Pernambuco (PE), Brazil; ${ }^{4}$ Doctor, Medical Sciences College (FCM)/University of Pernambuco (UPE). Recife (PE), Brazil; ${ }^{5}$ Nurse, Foundation of Higher Education of Olinda (FUNESO). Recife, Pernambuco (PE), Brazil. ${ }^{6}$ Nurse, Master in Physiology and Biochemistry from the Federal University of Pernambuco (UFPE). Recife; ${ }^{7}$ Nurse, Foundation of Higher Education of Olinda (FUNESO). Recife, Pernambuco (PE), Brazil; ${ }^{8}$ Nurse, Master in Intensive Care in Woman Health from the Institute of Integral Medicine Professor Fernando Figueiras (IMIP).Recife, Pernambuco (PE), Brazil; ${ }^{9}$ Nurse, Master in Nursing Care from the University of Pernambuco/Paraíba State University (UPE/UEPB), Recife, Pernambuco (PE)/Campina Grande, Paraíba (PB), Brazil; ${ }^{10}$ Nurse, Specialist in Intensive Care Unit (ICU) Adult Emergency from the Nursing School Nossa Senhora das Graças/University of Pernambuco (FENSG/UPE). Recife, Pernambuco (PE), Brazil; ${ }^{11}$ Grater in Pharmacy from the Estácio de Sá College. Recife, Pernambuco (PE), Brazil; ${ }^{12}$ Grater in Nursing from the Brazilian University Center (UNIBRA). Recife, Pernambuco (PE), Brazil.

\section{ARTICLE INFO}

Article History:

Received $03^{\text {rd }}$ April, 2020

Received in revised form

$16^{\text {th }}$ May, 2020

Accepted $04^{\text {th }}$ June, 2020

Published online $30^{\text {th }}$ July, 2020

\section{Key Words:}

Behavior; Fatigue; Health impacts; Women; Breast Neoplasms; Chemotherapy.

*Corresponding author:

Liniker Scolfild Rodrigues da Silva

\begin{abstract}
Objective: The aim of the present study was to characterize fatigue in women with breast cancer who underwent chemotherapy treatment under the behavioral dimension of the Revised Piper Scale. Materials and Methods: This is a descriptive, cross-sectional study with a quantitative approach, conducted at the Outpatient Clinic of a Breast Pathology Clinic of the Pernambuco Cancer Hospital $(\mathrm{PCH})$. The data collection procedure was performed through the Free and Informed Consent Term (FICT) for each of the 317 women and subsequently responded to the collection instrument for the Piper Revised Fatigue Scale. Results: Results show that fatigue interferes with the ability to complete work or school activities significantly in women. Regarding the intensity of stress caused by fatigue, it was found that 117 women (36.9\%) answered values equal to or lower than the cutoff point, while 200 women $(63.1 \%)$ scored values in the range of five to ten. Conclusion: The importance of further studies that address the impact of side effects of chemotherapy treatments on women's lives is highlighted, as it directly and indirectly reflects on the emotional state, favoring increased stress and, consequently, increasing the prevalence of fatigue.
\end{abstract}

Copyright (C) 2020, Cristina Albuquerque Douberin et al. This is an open access article distributed under the Creative Commons Attribution License, which permits unrestricted use, distribution, and reproduction in any medium, provided the original work is properly cited.

Citation: Cristina Albuquerque Douberin, Liniker Scolfild Rodrigues da Silva, Talita Munique de Melo Rodrigues, Edivaldo Bezerra Mendes Filho, Adriana Maria dos Santos, Thayná da Silva Constantino, Yanna Georgia Crispiniano Ferreira da Silva, Adriane Farias Patriota, Luiz Neves Silveira Filho, Luciana Maria da Silva, Rosimery Rodrigues de Almeida Mendes, Livia Maria Almeida de Oliveira, 2020. "Characterization of fatigue in women with breast neoplasia submitted to chemotherapy under the behavioral dimension of the piper scale-revised”, International Journal of Development Research, 10, (07), 38584-38587.

\section{INTRODUÇÃo}

Considered as one of the chronic non-communicable diseases (NCDs) that has been affecting people of the world population most recently, cancer is characterized by being stigmatized by fear and the potential risk of life (Cardozo, 2011). Regarding the types of cancers, it is worth mentioning that they are numerous and as varied as possible, depending on their location and extent. Among these forms is breast cancer, which can be considered as the second most common cancer in the world and the most common among women (Inumaru et al., 2011). The worldwide incidence of breast cancer varies widely, occurring in more than half of cases in industrialized countries 
(Lisboa, 2009). North America, some countries in Europe (Western and Northern) and Australia have the highest incidence of breast cancer. The countries of Eastern Europe, South America, South Africa and East Asia express intermediate incidence, while African and Asian populations have the lowest rates (Parkin et al., 2006). Regarding the specific case of the Brazilian reality, the high incidence rates for breast cancer have been following the worldwide trend (Brasil, 2008). Estimates from the National Cancer Institute (INCA) for the incidence of this female cancer in 2014 were 57,120 cases (INCA, 2013). In the case of the Northeast, in 2010, INCA estimated the occurrence of 8,270 new cases of breast cancer. More specifically, there are data referring to the state of Pernambuco, having been in him and also in the city of Recife, in 2003, the most incident tumor (Gurgel, 2011). The gross incidence rate went from 34.69 per 100,000 women in 2003 to 46.35 per 100,000 women in 2010 . In Recife, the rate went from 79.35 per 100,000 women in 2003 to 84.25 per 100,000 women in 2010, which represented the second position in the list of cancers (PERNAMBUCO, 2010). It is also noteworthy that breast cancer is responsible for $14 \%$ of the total deaths associated with cancer among women worldwide (Inumaru et al., 2011). One of the most commonly used treatments to combat breast cancer is chemotherapy (CT), which triggers a diverse symptomatology between nausea and prolonged and constant states of fatigue. In fact, fatigue is often reported by subjective sensations originating from tiredness, physical and mental exhaustion, weakness, lack of energy and exhaustion to perform various activities of daily living (Brazilian Fatigue Consensus, 2010). It should be noted that this side effect is almost universally present in the life of patients with some type of cancer undergoing chemotherapy treatment, which can be expressed by a prevalence of 25 to $99 \%$ of cases (Scholberg et al., 2014).

In the specific case of breast cancer, it can be said that fatigue has been recognized as one of the most common and problematic symptoms (Huang et al. 2014), reaching $30 \%$ of patients at the time of diagnosis, as well as revealing an increasing prevalence of 60 to $96 \%$ during the treatment phase (Noal et al., 2011), still reaching about 25 to $33 \%$ of survivors after the chemotherapy period (Orre et al., 2011). Interpreting fatigue from the normal physiological point of view, which for healthy individuals translates as a protective response to situations of physical and/or psychological stress, being ended with a rest, for cancer patients, including breast cancer, this symptom is considered painful, exhausting, unpleasant, and heart breaking, and cannot be relieved with rest (Lamino; Mota; Pimenta, 2011).The etiology of fatigue is still obscure, but as a symptom it can be said that its origin is multifactorial, since psychological, physical and social factors are capable of triggering it (Menezes; Camargo, 2006). Therefore, according to Menezes and Camargo (2006), it is noticeable that one is ahead of a symptom with a panorama whose elaboration of goals to achieve its prevention or even resolution is made difficult. There is a need to reduce the impact that fatigue has on the lives of these patients, and it is important to manage it as a symptom, increasing their knowledge and management, so that the assistance provided to these women during chemotherapy is improved (Silva, 2013).

Thus, it can be seen that fatigue induced by chemotherapy therapy reveals a condition of immense difficulty to maintain the lifestyle of patients with breast cancer, this allows their insertion at the top of the list of symptoms most easily found among them and, therefore, deserves special attention from health professionals regarding their detection and evaluation. Thus, some common problems are highlighted: breast cancer (more prevalent and feared by women) and the symptom of fatigue often caused by antineoplastic chemotherapy (usually experienced by patients with breast cancer). In order to identify the presence of fatigue as a chemotherapeutic side effect in women with breast cancer, expanding its disclosure in the literature, a guiding question based the interest on the study: What is the intensity of fatigue under the behavioral dimension of the Revised Piper Scale in women with breast cancer undergoing chemotherapy? And your answer was the objective of the study.

\section{MATERIALS AND METHODS}

This was a descriptive, cross-sectional study with a quantitative approach, which was conducted at the Ambulatory Unit of a specialized clinic for breast pathology at the Pernambuco Cancer Hospital (PCH), from September to November 2015. The PCH is characterized by being an institution that began its activities in a philanthropic manner on November 9, 1945. From its inception to the present day, it has become a reference in its field of activity in the North and Northeast of Brazil and, throughout its trajectory, plays the role of assisting cancer patients, as well as informing the population about the importance of prevention of this problem. From April 10, 2007, it was controlled by the state of Pernambuco, treating more than half of cancer patients in that state. The sample calculation was based on the proportion estimate, since it was intended to identify it for the amount of women with breast cancer undergoing chemotherapy who feel fatigue. Considering that the monthly average of patients with breast cancer undergoing chemotherapy in the PCH was $1800(\mathrm{~N})$ and some constant statistical values, such as $95 \%$ confidence level $(\mathrm{z}=$ $1.96)$ and error (e) or (d) of $5 \%$, a sample (n) of 317 patients was obtained, based on a finite population. In this case, the sample proportion (p) and its complement (q) were taken with the same value of 0.5 , which provides the largest possible sample for the population considered for the sample calculation, from the formula below:

$n=\frac{Z^{2} \cdot p \cdot q \cdot N}{d^{2}(N-1)+Z^{2} \cdot p \cdot q}$

Inclusion criteria were female breast cancer patients undergoing outpatient chemotherapy treatment at the $\mathrm{PCH}$, aged 18 years and over and with communication skills for reading and writing comprehension. As exclusion criteria, there were female patients in divergent treatment modality of chemotherapy. Regarding the variables, it can be said that fatigue corresponds to the qualitative and dependent variable of the study, which was evaluated through the following instrument: Piper Fatigue Scale - Revised (PIPER). This is a multidimensional self-report instrument for fatigue assessment, which was developed by Piper et al. In 1998, using the Piper Fatigue Scale (PFS) proposed by Piper et al. in 1989, and which had recent validation for the Portuguese language in 2009 (Mota; Pimenta; Piper, 2009). The original version of Piper is made up of 27 items, but the Brazilian (which will be discussed here) is made up of 22, among which are three main dimensions: behavioral dimension (items 2 to 7), affective dimension (items 8 to 12) and sensory / psychological dimension (items 13 to 23). Among these, the behavioral dimension will be analyzed here. Regarding its gradation, it can be said that for each dimension evaluated, it has scores from 0 to 10 , and the cut-off point is set to score 4. For fatigue to be clinically significant, therefore, the score must be greater than 4 . The average of all items corresponds to the total score and each dimension has its scores calculated by the average of the items contained therein. The collected data was first entered into spreadsheets using Microsoft Excel software and later transferred and analyzed using a descriptive quantitative approach using the Statistical Package for Social Science (SPSS) version 21.0 software. To characterize fatigue, the symptom was analyzed from the perspective of its absolute frequencies and percentages, taking into account the cutoff point identifying its presence as being recommended by score 4 (if the score is equal to or less than 4 , will mean no fatigue, but if greater than 4 , fatigue will be present) (NCCN 2010; Mansano-Schlosser; Ceolim, 2014). The description and analysis of the behavioral dimension (items 2 to 7) of the Piper Fatigue Scale - Revised were performed, taking into account the mean scores for items inherent to it. The data collection procedure was performed as follows: the Free and Informed Consent Term (FICT) was delivered, read and explained to each of the 317 women at the time they were undergoing chemotherapy at the PCH outpatient clinic. When they accepted to participate in the research, they signed it, showing agreement, and soon after they responded to the Piper Fatigue Scale - Revised collection instrument. This study corresponds to a clipping of a Master's dissertation submitted to and approved by the Research Ethics Committee (REC) of the Pernambuco Cancer 
Society under CAAE No. 45583415.0.3001.5205; and defended by the author by the Associate Postgraduate Program in Nursing of the University of Pernambuco / Paraíba State University (UPE / UEPB), in May 2016.

\section{RESULTS}

The behavioral dimension covers the items of the scale from 2 to 7 . The topics that obtained the highest average were the third and the sixth, each with a 6.03 average, which allows us to infer a higher prevalence regarding the composition of fatigue indicated by the patients. On the other hand, the fifth topic is considerably highlighted because it revealed an average of only 3.47, that is, the smallest within the dimension and outside the range considered in the literature as fatigue, since chemotherapy fatigue was not responsible for the changes in the sex life of these women, but other reasons. Such results can be seen in table 1 . Regarding the intensity of stress caused by fatigue, it was found that 117 women (36.9\%) answered values equal to or lower than the cutoff point, while 200 women $(63.1 \%)$ scored values in the range of five to ten. In item number three, which proposed to know how much fatigue interferes with the ability to complete work or school activities, it was found that only 94 women $(29.7 \%)$ mentioned values in the range of zero to four; but $223(70.3 \%)$ answered values from five to ten. Noteworthy is the scale's ten value, as it obtained 70 answers (22.1\%), expressing a significant percentage of women who find it very difficult to complete their work or school activities. Scale topic number four addressed the amount of interference of fatigue on the ability to visit or be with friends. It was found that 122 women (38.5\%) reported values within the range of zero to four on the scale and 195 of them $(61.5 \%)$ scored values from five to ten. There are also a significant percentage of respondents $(21.5 \%)$ who indicated the maximum value on the scale, which refers to the difficulty in visiting or being with their friends due to the fatigue caused by chemotherapy.

Table 1. Mean and standard deviation of Piper Fatigue Scale Behavioral Dimension Items - Revised. Recife, Pernambuco (PE), Brazil, 2015.

\begin{tabular}{|l|c|c|}
\hline \multicolumn{1}{|c|}{$\begin{array}{c}\text { Revised Piper's Fatigue Scale ITEMS } \\
\text { Behavioral dimension }\end{array}$} & Average & $\begin{array}{c}\text { Standard } \\
\text { deviation }\end{array}$ \\
\hline $\begin{array}{l}\text { 2. How much stress does the fatigue you } \\
\text { feel now cause? (No stress / Too much } \\
\text { stress) }\end{array}$ & 5.32 & 3.34 \\
\hline $\begin{array}{l}\text { 3.How much does fatigue interfere with } \\
\text { your ability to complete your work or } \\
\text { school activities? (Not at all / A lot) }\end{array}$ & $\mathbf{6 . 0 3}$ & $\mathbf{3 . 3 4}$ \\
\hline $\begin{array}{l}\text { 4. How much does fatigue interfere with } \\
\text { your ability to visit or be with your } \\
\text { friends? (Not at all / A lot) }\end{array}$ & 5.49 & 3.65 \\
\hline $\begin{array}{l}\text { 5. How much does fatigue interfere with } \\
\text { your ability to have sexual activity? (Not } \\
\text { at all / A lot) }\end{array}$ & 3.47 & 3.97 \\
\hline $\begin{array}{l}\text { 6. Overall, how much fatigue interferes } \\
\text { with your ability to perform any type of } \\
\text { activity you enjoy? (Not at all / A lot) }\end{array}$ & $\mathbf{6 . 0 3}$ & $\mathbf{3 . 5 2}$ \\
\hline $\begin{array}{l}\text { 7. How would you describe the intensity or } \\
\text { magnitude of fatigue you are experiencing } \\
\text { right now? (Light/Intense) }\end{array}$ & 5.03 & 3.60 \\
\hline Behavioural dimension & $\mathbf{5 . 2 3}$ & $\mathbf{2 . 5 1}$ \\
\hline
\end{tabular}

Source: Own elaboration.

Regarding item number five of the scale, which sought to investigate the amount of interference of fatigue on sexual performance ability, it was observed that a considerable portion of the interviewees, 191 women $(60.3 \%)$, answered values within the range of zero to four on the scale; however, 126 clients $(39.7 \%)$ answered values within the range of five to ten. It is worth emphasizing that almost half of the clientele, ie 157 patients $(49.5 \%)$, scored the lowest end (zero) of the scale as a response, demonstrating that fatigue did not interfere with their sexual activity. Question six on the scale, which measured the interference of fatigue on the ability to perform any type of activity that is generally liked, revealed that 102 women $(32.2 \%)$ chose to score from zero to four on the scale and 215 of them $(67.8 \%)$, five to ten. For topic seven of the scale, which aimed to identify the description of the intensity or magnitude of fatigue felt at the time, the results revealed were 137 women $(43.2 \%)$ who chose values from zero to four, as well as 180 of them $(56,8 \%)$ that marked values ranging from five to ten. It is worth emphasizing that $18.9 \%$ of women scored the low end of the scale as a response, demonstrating that they considered the magnitude of mild fatigue, but a similar percentage $(18.3 \%)$ of them marked the high end, ie considering the magnitude of fatigue they felt intensely.

\section{DISCUSSION}

Regarding the analysis of the identification of the presence of fatigue in the items of the Piper Scale inserted in the behavioral dimension, it was found that it significantly influenced the patients' lifestyle, causing them to modify it in some aspect in five out of six topics of that dimension. Item two of the aforementioned dimension revealed that most patients felt stressed by the fatigue felt at the time of the interview. Thus, there is a considerable correlation between stress and fatigue. Similar results were found in the study by Ishikawa, Derchain and Thuler (2005), who stated that there is a direct association between stress level and fatigue. Lôbo et al. (2014), when studying quality of life of women with breast cancer chemotherapy, found that their patients were not very stressed, but for those who were, had their source in fatigue, one of the physical effects from chemotherapy. From item three, it was found that most of the patients were fatigued to such an extent that fatigue began to interfere with their ability to complete work or school activities. Ishikawa, Derchain and Thuler (2005) also reported that fatigue interfered with the patients' work activities. Santos et al., (2013), identified similar results, revealing that fatigue caused losses in the performance of work activities. These findings suggest that fatigue is a disabling body symptom that implies the installation of extreme tiredness in the muscles of these patients, thus negatively affecting the performance of such tasks (Schmidt et al., 2012; Reindustatter et al., 2011). The absence of work recorded in most women is related to the treatment recommended by the disease, as well as the fact that fatigue is an effect of it, also support and justify such finding. Findings in item four indicated that $61.5 \%$ of women felt fatigued enough to be deprived of visiting or being with their friends. Ishikawa, Derchain and Thuler (2005) achieved similar results when they mentioned that fatigue interfered with the way patients relate to each other. Schmidt et al., (2012), andReidunsdatter et al., (2011),also saw that socialization is negatively influenced by fatigue. On the other hand, Lôbo et al., (2014),found that physical condition was not able to interfere with family life and social activities. The corroborative results are more relevant, as patients claimed to feel unwilling to visit, preferring to be isolated and lying in bed doing absolutely nothing.

In this study, it was not possible to ascertain whether fatigue impaired sexual activity. This is because many of them confessed that they no longer had a partner (widows) or were abandoned by them after the diagnosis of the disease with the consequent submission to mastectomy, not having an active sex life, so long ago. This information serves as a foundation to justify why almost half of the sample $(49.5 \%)$ marked the minimum extreme value (zero) on the scale. Considerable number of findings in the literature contradict the result of this study, because although mastectomy causes a worsening of sexual life, fatigue was considered as justification for the decrease of sexual desire and frequency of sexual intercourse in the studies by Talhaferro, Lemos and Oliveira (2007), Ming (2002), Cesnik and Santos (2012) and Verenhitach et al., (2014). Thus, it is noted that sexual functioning problems are common in women with breast cancer undergoing chemotherapy treatment, because fatigue is a direct symptom of this therapy, which was not found in preponderance in this study. With regard to the interference of fatigue on the ability to perform any type of activity that one likes, in general, item six detected that most women outlined fatigue as a hindrance in this performance. Similar results were identified by Tralongo, Respini and Ferraù (2003), Schmidt et al. (2012), Reidunsdatter et al. (2011), and byLôbo et al., (2014). It is concluded, therefore, that fatigue 
arising from chemotherapy treatment in breast cancer is an important compromising interest in performing pleasure or leisure activities. Finally, item seven measured that most women described their fatigue for the moment as being of intense magnitude. This finding corroborates that found by Lamino et al. (2011), when they state that $33.3 \%$ of their patients quantified their fatigue as moderate or severe. This fact increasingly contributes to the consolidation of the idea that fatigue is a devastating symptom of chemotherapy.

\section{CONCLUSION}

Through the revised Piper scale to detect the interference level of fatigue in women with breast cancer undergoing chemotherapy treatment, the results of the present study revealed that most women report fatigue at high levels, interfering with work, school activities, social interaction with friends, also including enjoyable activities. Among the activities addressed in the scale, the interference of fatigue on sexual performance was shown to have little relationship, however, when questioned, the women said they had no partner or because they were abandoned by them after the diagnosis of the disease, justifying the reason why most responses assured that fatigue did not interfere with sexual activity. Given this, it is extremely important strategies to reduce the interference of fatigue in the lives of these women. It is known that despite being a side effect of chemotherapy treatment, there are studies that address therapies that seek to improve the quality of life, both physically and emotionally. It is noteworthy that it was found in the interviewees' speech a considerable correlation between stress and fatigue, which reinforces the need for interventions especially at the emotional level. Finally, we emphasize the importance of further studies that address the impact of side effects of chemotherapy treatments on women's lives, including especially when they undergo the mastectomy procedure, significantly interfering with self-image, directly and indirectly reflecting on their emotional state, favoring increased stress and consequently increasing the prevalence of fatigue.

Aknowledgements: The acknowledgments of this work go to the patients in treatment approached in interview; as well as to the multiprofessional health team that was very receptive to us during this study.

\section{REFERENCES}

Brasil. Ministério da Saúde (2008). Instituto Nacional do Câncer. Ações de enfermagem para o controle do câncer. $3^{\mathrm{a}}$ ed. Rio de Janeiro: INCA.

Cardozo FMC(2011). A influência da depressão e fadiga na qualidade de vida dos pacientes oncológicos submetidos à quimioterapia. Dissertação (Mestrado) - Escola de Enfermagem de Ribeirão Preto/USP, Ribeirão Preto.

Cesnik VM, Santos MA(2012). Desconfortos físicos decorrentes dos tratamentos do câncer de mama influenciam a sexualidade da mulher mastectomizada? Rev. Esc. Enferm. USP.46(4):10011008.

Consenso Brasileiro de Fadiga(2010). Fadiga em cuidados paliativos. Revista Brasileira de Cuidados Paliativos.3(2).

Gurgel MMS(2011).Câncer de mama: estágio no momento do diagnóstico em mulheres residentes do Recife - Pernambuco. Monografia (Programa de Residência Multiprofissional em Saúde Coletiva) - Departamento de Saúde Coletiva, Centro de Pesquisas Aggeu Magalhães, Fundação Oswaldo Cruz.

Instituto Nacional do Câncer (INCA). O que é câncer? (2013). Disponível em: <http://www2.inca.gov.br/wps/wcm/ connect/ cancer/site/oquee >. Acesso em: 6 ago. 2014.

Inumaru LE,Silveira EAD,Naves MMV (2011). Fatores de risco e de proteção para câncer de mama: uma revisão sistemática. Cad. Saúde Pública. 27(7):1259-1270.
Ishkawa NM, Derchain SFM, Thuler LCF (2005).Fadiga em pacientes com câncer de mama em tratamento adjuvante. RevistaBrasileira de Cancerologia. 51(4):313-318.

Lamino DA, Mota DDCF, Pimenta CAM (2011). Prevalência e comorbidade de dor e fadiga em mulheres com câncer de mama. Revista da Escola de Enfermagem de São Paulo. 45(2):508-514.

Lisboa LF (2009). Tendências da incidência e da mortalidade do câncer de mama feminino no município de São Paulo. Dissertação (Mestrado) - Faculdade de Saúde Pública da Universidade de São Paulo, São Paulo.

LôboAS, Fernandes AFC, Almeida PC, Carvalho CMR, Sawada NO (2014).Qualidade de vida em mulheres com neoplasias de mama em quimioterapia. Acta Paul. Enferm. 27(6):554-559.

Mansano-schlosser TC, Ceolim MF (2014). Fadiga em idosos em tratamento quimioterápico. Revista Brasileira de Enfermagem. 67(4):623-639.

Menezes MFB, Camargo TCA (2006). Fadiga relacionada ao câncer como temática na enfermagem oncológica. Rev. Latinoam. Enfermagem. 14(3):442-447.

Mota DDCF,Pimenta CAM, Piper BF (2009).Fatigue in Brazilian cancer patients, caregivers, andnursingstudents: a psychometric validationstudyofthe Piper Fatigue Scale-Revised. SuportCare Cancer. 17:645-652.

Ming VMW (2002). Psychological predictors of marital adjustment in breast cancer patients. Psychol. Health Med. 7(1):37-51.

National Comprehensive Cancer Network (NCCN) ClinicalPracticeGuidelines in Oncology (NCCN Guidelines ${ }^{\mathrm{TM}}$ ) Cancer Related-fatigue, version 1, 2011.

Noal S, Levy C, Hardouin A, Rieux C, Heutte N, Ségura C et al(2011).One-year longitudinal studyof fatigue, cognitivefunctions, andqualityoflife after adjuvant radiotherapy for breast cancer. Int. J. RadiationOncology Biol. Phys. 81(3): 795-803.

Orre IJ,Reinertsen KV, Aukrust P, Dahl AA, Fossa SD, Ueland T, Murison, R.(2011).Higherlevelsof fatigue are associated with higher CRP levels in disease-free breast cancer survivors. JournalofPsychosomaticResearch. 71:136-141.

Parkin DM,Férnandez LMG (2006). Use ofstatisticstoassesthe global burdenofbreastcancer. The BreastJournal.12:70-80.

Pernambuco, Secretaria de Saúde do Estado. Secretaria Executiva de Vigilância em Saúde. Diretoria Geral de Promoção, Monitoramento e Avaliação da Situação de Saúde. Câncer de mama no estado de Pernambuco. Recife, 2010. (Série Doenças Crônicas Não Transmissíveis n. 1).

Reidunsdatter RJ,Rannestad T, Frengen J, Frykholm G, Lundgren S.(2011). Early effects of contemporary breast radiation on health-related quality of life-predictors of radiotherapy-related fatigue. ActaOncol. 50(8):1175-1182.

Santos J, Mota DDCF, Pimenta CAM (2013). Co-morbidade fadiga e depressão em pacientes com câncer colo-retal. Revista da Escola de Enfermagem USP. 43(4).

Schmidt ME, Chang-Claude J, Vrieling A, Heinz J, Flesch-Janys D, Steindorf K.(2012). Fatigue and quality of life in breast cancer survivors: temporal courses and long-term pattern. J. Cancer Surviv. 6(1):11-19.

Silva MD (2013).As repercussões corporais vivenciadas pela mulher com câncer de mama decorrentes do tratamento quimioterápico: uma análise à luz da Teoria de SisterCallista Roy. Dissertação (Mestrado) -Faculdade de Enfermagem da Universidade do Estado do Rio de Janeiro, Rio de Janeiro.

Talhaferro B, Lemos SS, Oliveira E (2007).Mastectomia e suas consequências na vida da mulher. Arq. Ciênc. Saúde. 14(1):1722.

Tralongo P, Respini D, Ferrau F (2003).Fatigue andaging. Crit. Rev. Oncol. Hematol. 4:57-64.

Verenhitach BD, Medeiros JN, Elias S, Nazário ACP.(2014).Câncer de mama e seus efeitos sobre a sexualidade: uma revisão stemática sobre abordagem e tratamento. FEMINA.42(1). 